\title{
Hedonik Konut Fiyat Endeksini Etkileyen Faktörlerin Analizi
}

\author{
Murat AKKAYA ${ }^{1}$
}

Öz

Konut piyasası son yıllarda ekonomi içerisinde önemli bir paya sahiptir. Ayrıca konut piyasasının finansal piyasalarla önemli bir etkileşimi bulunmaktadır. Konut piyasası öncü gösterge olarak da kullanılmaktadır. Çalışmanın amacı T.C. Merkez Bankası'nca izlenen Hedonik Konut Fiyat Endeksi ve değişkenlerin arasındaki ilişkinin incelenmesidir. Ayrıca değişkenler arasındaki nedensellik ilişkilerine bakılmıştır. Çalışmada Otoregresif Dă̆ıtık Gecikme testi kullanılmıştır. Uzun dönemde Altın Fiyatı hariç belirlenen diğer değişkenlerin uzun dönemde Hedonik Konut Fiyat Endeksi üzerinde etkili olduğunu göstermektedir. İkinci aşamada nedensellik ilişkisine bakılmıştır. Granger Nedensellik Testine göre değişkenler arasında nedensellik ilişkileri tespit edilmiştir.

Anahtar Kelimeler: Hedonik Konut Fiyat Endeksi, Türkiye, Makroekonomik Değişkenler, ARDL Testi, Granger Nedensellik Testi

Jel Kodlart: C43, E00, C43

\section{An Analysis Of Factors Affecting Hedonic Housing Pricing Index}

\begin{abstract}
The housing market has an important share in the economy in recent years. There is also an important interaction between the housing market and financial markets. The housing market is also used as a leading indicator. The aim is to investigate the relationship between Hedonik Housing Price Index prepared by Central Bank of Turkish republic and variables. In addition, causality relations between variables are examined. ARDL Test results indicate that variables excluding the Gold Price have effect on the Hedonic House Price Index in the long run. Granger Causality Test results also indicate the causality relationships between the variables.
\end{abstract}

Keywords: Hedonik Housing Price Index, Turkey, Macroeconomic Variables, ARDL Test, Granger Causality Test.

Jel Codes: C43, E00, C43

\footnotetext{
${ }^{1}$ Dr. Öğr. Üyesi, T.C. İstanbul Arel Üniversitesi, İ̈BF, Uluslararası Ticaret Finans Bölümü (İngilizce), muratakkaya @ arel.edu.tr, ORCID: 0000-0002-7071-8662
} 


\section{AKKAYA}

\section{GİRIŞ}

Gelişmiş ekonomilerde konut piyasası gayri safi yurtiçi hasıla (GSYIH) içerisinde önemli bir paya sahiptir. Konut alımı ve harcamaları tüketici harcamaları içerisinde büyük bir yer tutmaktadır. Bu itibarla konut piyasası ve makroekonomik değişkenler arasında bir ilişkinin olması beklenmektedir. Ayrıca konut fiyatlarının makroekonomik değişkenlerden etkilenmesi de beklenen bir sonuçtur. Konut fiyatlarındaki dalgalanmalarda makroekonomik değişkenlerin etkili olduğu yapılan çalışmalarda görülmüştür. Konut fiyatlarında satın alan bireylerin veya kurumların kararları doğrudan etkili olmakla birlikte makroekonomik durum da önemli bir rol oynamaktadır.

Konut fiyatları ve harcamaları piyasalarda öncü gösterge olarak da kullanılmaktadır. Ayrıca konut kredileri bankacılık kredi hacminin önemli bir kısmını oluşturmaktadır. Konut fiyat endeksleri, bankalar ve finansal kurumların aktif/pasif yönetimi ve risk yönetiminde çok önemlidir. Oluşturulan konut fiyat endeksleri ekonominin tahmini için gösterge olarak da kullanılmaktadır ve 2008 Küresel Kriz ile birlikte finansal piyasalarda izlenmektedir.

Türkiye'de T.C. Merkez Bankası tarafından aylık Konut Fiyat Endeksi (KFE) verileri açıklanmaktadır. Konut Fiyat Endeksi, konut piyasasındaki değişimleri ölçmek için tabakalanmış ortanca fiyat yöntemini kullanmaktadır. Gayrimenkul değerleme şirketlerince hazırlanmış değerlenme raporlarından veriler derlenmektedir. Konut Fiyat Endeksi'nde konutun konumu (şehir, ilçe, mahalle, cadde vb.), brüt ve net $\mathrm{m}^{2}$ alanı, inşa yılı, kalite, site güvenliği ve asansör vb. gibi gözlemlenebilen özellikler kullanılmaktadır. Konut Fiyat Endeksi zincirleme Laspeyres yöntemi ile hesaplanmaktadır (T.C. Merkez Bankası. 2016).

Konut fiyat endekslerindeki en önemli sorunlardan biri fiyatların derlenmesinde kullanılan kaynaklardır. Ayrıca konumsal özellikler (merkeze olan yakınlık, manzara durumu vb.), yapısal özellikler (yeşil ve sosyal alan, oda ve banyo sayısı, bina yaşı vb.) ve sosyo-ekonomik nitelikler (hemşerilik, güvenlik, metro, okul, hastane yakınlık vb.) konutun fiyatını etkilemektedir. 
Konut fiyat endeksi hesaplamasında birçok yöntem kullanılmaktadır.
a. Hedonik Fiyat Modeli
b. Satış Fiyatı Değerleme Tutarı Oranı Modeli
c. Tekrarlanan Satışlar Modeli,
d. Örnek Konut Modeli,
e. Medyan-Ortalama Fiyat Modeli,
f. Karışım Arındırma Modeli,
g. Hibrid Model,

Konutların fiyatlamasında tüketici tercihleri ve inovasyon kaynaklı kalite değişimleri de etkili olabilmektedir. Ayrıca, konut piyasasındaki yüksek çok türlülük, konutlardaki kalite farklılıklarının fiyatlar üzerindeki etkisini belirlemeyi zorlaştırmaktadır. Ayrıca konut fiyatlarındaki değişimler iki kaynaktan oluşmaktadır: saf fiyat değişimleri ve kalite değişimleri. Saf fiyat değişimleri ile kalite değişimlerini ölçmede hedonik fiyat modeli, tekrarlanan satışlar modeli ve hibrit modeller kullanılmaktadır. Hill (2011)'e göre diğer yöntemlerin zayıflıklarından dolayı hedonik endeksler yaygın bir şekilde kullanılmaktadır.

Hedonik yöntemde konutun özellikleri baz alınarak endeks oluşturulmaktadır. $\mathrm{Bu}$ yöntemde, konutun gözlemlenebilen özellikleri kontrol edilebilmektedir. Ayrıca saf fiyat ve kalite değişimlerinin belirlenmesini olanaklı hale getirmektedir (Kunovac ve diğ., 2008).

Hedonik yöntem zaman kukla değişkeni tekniği ve karakteristik fiyat yöntemine ayrılmaktadır. Zaman kukla değişken yönteminde yeni veri ile geçmişe yönelik gözden geçirme zorunluluğu bulunmaktadır. Karakteristik fiyat yöntemi ise sadedir. Bu nedenle kurumlar karakteristik fiyat yöntemini tercih etmektedirler. Karakteristik fiyat yönteminde izlenen konut özelliklerine ait gölge fiyatların tahmininde hedonik regresyon modellerinden yararlanılmaktadır. 


\section{AKKAYA}

Hedonik regresyon yöntemi, konutun kaliteden kaynaklanan değişimleri kontrol edebilmektedir. $^{2}$

Hedonik fiyat yöntemi, Waugh (1928) tarafından ilk olarak kullanılmıştır. Terim olarak ise Court (1939) tarafından kullanılmış ve Griliches (1961) ve Rosen (1974) bu modeli yaygınlaştırmıştır. İlk hedonik konut fiyat endeksi olan Müstakil Konut Fiyat Endeksi (One-Family Houses Index) ABD Nüfus İdaresi tarafindan 1998 yılında yayımlanmıştır.

$\mathrm{Bu}$ model, bir malın fiyatını, malın özelliklerinin değer toplamları olarak değerlendiren ve her bir özelliğin değerini regresyon analizi ile tahmin eden bir yöntem olmaktadır (Shimizu ve diğerleri, 2010).Bu modelde, konutun fiyatı ile konutun sahip olduğu yapısal özellikler, konutun bulunduğu yer ve yere ait özellikler arasındaki ilişki kurulmaktadır. Modelde bağımlı değişken konutun fiyatıdır. Bağımsız değişkenler ise konutun fiyatına etki eden konutun sahip olduğu yapısal özellikler ile diğer değişkenlerdir (Kaya, 2012).

"Hedonik fiyat fonksiyonu kullanılarak hesaplanan endekse hedonik fiyat endeksi denmektedir. Hedonik fiyat endekslerini hesaplamada temelde kullanılan dört yöntem bulunmaktadır.

- Zaman Kukla Değişkeni Yöntemi

- Özellik Fiyatları Endeksi Yöntemi

- Hedonik Fiyat Tahmin Yöntemi

- Kaliteye Göre Hedonik Düzeltme Yöntemi” 3

2010-2017 Mart döneminde Türkiye'de Hedonik konut Fiyat Endeksi \% 107,33 oranında yükselmiştir (Şekil 1). Küresel likidite bolluğu, GSYİH artış1, Türk bankacılık sektörü kredi hacminin genişlemesi, ipoteği dayalı kredi faizlerinin düşmesi, nüfus artışı ve büyük kentlere göçler bu dönemde konut fiyatlarının artmasına sebep olmuştur. Nüfus artışının ve büyük şehirlere göçün devam

${ }^{2}$ T.C. Merkez Bankası (2016: 2-3)

${ }^{3}$ Kaya (2012: 69) 
etmesi, kentsel dönüşüm ile eski yapıların yenilenmesi ile birlikte konut ihtiyacının artacağı beklenmektedir.

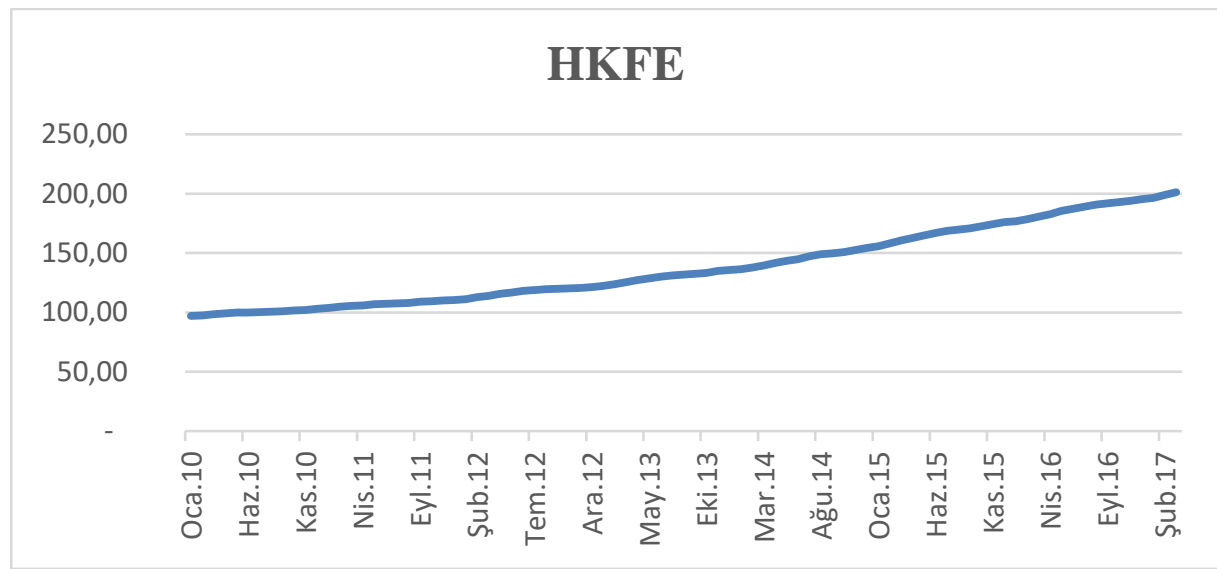

Şekil 1. Hedonik Konut Fiyat Endeksi (HKFE)

Kaynak: T.C. Merkez Bankası

Türkiye'de akademik alanda genellikle konut fiyatları ile makroekonomik göstergeler arasındaki ilişkileri araştıran çalışmalar bulunmaktadır. Hedonik yöntemin kullanıldığı çalışma sayısı sınırlıdır. Bu çalışmanın amacı T.C. Merkez Bankası'nca izlenen Hedonik Konut Fiyat Endeksi ve değişkenlerin arasındaki ilişkinin incelenmesi ve makroekonomik değişkenlerin belirlenmesidir. $\mathrm{Bu}$ amaçla Ocak 2010 - Mart 2017 döneminde Hedonik Konut Fiyat Endeksi ve değişkenler arasındaki uzun dönem ilişkilere ARDL (Autoregressive Distibuted Lag) testi ile bakılacaktır. Ayrıca değişkenler arasındaki nedensellik ilişkileri de araştırılmıştır. $\mathrm{Bu}$ çalışma ile konut yatırımcılarına, piyasa oyuncularına ve ekonomik karar vericilere öncü gösterge niteliğinde bilgilerin sağlanması hedeflenmiştir.

\section{LITERATÜR ARAŞTIRMASI}

Hedonik Fiyat Modeli konut piyasasında Ridker ve Henning (1967) tarafindan uygulanmıştır. Çalışmada En Küçük Kareler yöntemi kullanılarak hava kirliliği ile hane halkının konut tercihlerini araştırmışlardır. Literatürde hedonik fiyat modelini uygulayan çok sayıda çalışma bulunmaktadır (Kain ve Quigley (1970), 


\section{AKKAYA}

Straszheim (1973), Straszheim (1974), Goodman (1978), Palmquist (1984), Mendelsohn (1984), Bartik (1987), Goodman (1998), Kim (1992), Leishman (2001), Bover ve Velilla (2002), Ogwang ve Wang (2002), Filho ve Bin (2003), Li, Prud'Homme ve Yu (2006), Bourassa, Cantoni ve Hoesli (2007), Wilhelmsson (2008), Widlak ve Tomczyk (2010))

Goodman (1978) Hedonik yöntemle Metropollerde konut fiyat endeksi oluşturmayı amaçladığı çalışmasında 15 alt piyasa, heterojen zaman ve yer kullanarak kısa dönemli denge modeli kullanmıştır. Çalışmada alt piyasalardaki komşuluk ve yapısal etkilerin yanı sıra şehir merkezlerinde kenar mahallelere göre ev fiyatlarının daha yüksek olduğu bulunmuştur.

Türkiye konut piyasasına yönelik çalışmalarda genellikle konut fiyatları ile makroekonomik göstergeler arasındaki ilişkilere bakılmıştır (Yankaya ve Çelik (2005), Baldemir ve diğerleri (2007), Badurlar (2008), Kargı (2013), Bekmez ve Özpolat (2013)).

Türkiye'de konut fiyatlarının analizinde Hedonik yöntemin kullanıldığı sınırlı çalışma bulunmaktadır (Üçdoğuk (2001), Yankaya ve Çelik (2005), Mutluer (2008), Selim (2008), Selim ve Demirbilek (2009), Cingöz (2010), Kaya (2012), Kördiş, Işık ve Mert (2014)).

Üçdoğruk (2001) konut satış fiyatı ve konutun özellikleri (pencere doğrama, çatı yalıtımı, oda sayısı vb.) arasındaki ilişkiye bakmıştır. Wald68 -F istatistiği ve Hendry'in genelden özele yaklaşımını ile en iyi hedonik fiyat modelini belirlediği çalışmada, kısıtlanmış modelin kısıtlanmamış modelden üstün olduğu görülmüştür. Yankaya ve Çelik (2005) ise İzmir metrosu ile konut fiyatları arasındaki ilişkiye bakmışlardır. Metro-otobüs durağına yürüyüş aralığı ve bina yaşı ile konut fiyatları arasında negatif bir ilişki bulunmuştur. Ayrıca konutun büyüklüğü ve katı, kalorifer durumu ve yapı kalitesinin ise konut fiyatlarını pozitif yönde etkilediği görülmüştür. Selim (2008) ve Selim ve Demirbilek (2009) yatay kesit verisi ile konut fiyatlarının belirleyen değişkenleri analiz etmiş̧tir. Türkiye'yi kapsayan bir veri seti ile hedonik konut fiyat endeksi serisi 
oluşturulmuş ve konut kiralarını etkileyen unsurların konutun büyüklüğü ve tipi, oda sayısı ve su sistemi, havuz, doğal gaz gibi konutun yapısal özellikleri olduğu bulunmuştur.

Cingöz (2010) ise konut fiyatlarını etkileyen değişkenleri araştırmış ve İstanbul'da siteler üzerine çalışmıştır. Fiyat ve semt, site içerindeki çocuk alanı, park, havuz-suni gölet, oda sayısı ve konut büyüklüğü arasında pozitif ilişki bulunmaktadır. Ancak konutun şehir merkezine uzaklığı fiyatı negatif etkilemektedir. Baldemir, Kesbiç ve İnci (2007) Muğla merkez için bir çalışma yapmışlardır. Cingöz (2010) ile benzer sonuçlar tahmin edilmiştir. Kaya (2012) T.C. Merkez Bankası için yapılan çalışmasında Aralık 2010 - Haziran 2012 döneminde zaman kukla değişken yöntemini kullanarak konut fiyatlarını etkileyen değişkenleri hedonik fiyat yöntemi ile belirlemiştir. Cingöz (2010) ve Baldemir, Kesbiç ve İnci (2007) ile benzer sonuçlar tahmin edilmiştir. Kördiş, Işık ve Mert (2014) ise benzer çalışmayı Antalya için yapmıştır. Çalışma sonucu diğer iller için yapılan çalışmalarla benzerlik göstermektedir. Antalya'da konut fiyatlarını konutun genişliği, bölgenin sosyoekonomik statüsü, deniz manzarası, kapalı oto park, 1sınma sistemi, asansör bulunması ve denize yakınlının etkilediği görülmüştür.

\section{VERILLER - YÖNTEM}

Araştırma Ocak 2010 - Mart 2017 dönemini kapsamaktadır ve toplam 87 adet aylık gözlemi içermektedir. Çalışmada, T.C. Merkez Bankası tarafından hazırlanan Hedonik Konut Fiyat Endeksi (HKFE) ve konut fiyatları üzerinde etkisi olduğu düşünülen altın fiyatı (ALTIN), Borsa İstanbul getiri endeksi (BIST-G), imalat sanayi kapasite kullanım oranı (ISKKO), işsizlik oranı (IO), TÜFE bazlı Reel Kur Endeksi (RDK), sanayi üretim endeksi (SUE), T.C. Merkez Bankası Bileşik Öncü Gösterge (TCMBBOG), TUIKK Tüketici Güven Endeksi (TGE), tüketici fiyatları fiyat endeksi (TFFE), USD döviz kuru (USD) verileri aylık olarak incelemeye eklenmiştir. 


\section{AKKAYA}

Modele eklenen makroekonomik değişkenlerin seçiminde Türkiye'de yatırımcıların en çok tercih ettikleri altın, ABD Doları ve hisse senedi fiyatları ve yatırımcı tercihine etkilediği düşünülen TÜFE bazlı Reel Kur Endeksi ve T.C. Merkez Bankası Bileşik Öncü Gösterge tercih edilmiştir. Ayrıca konut piyasası ile ilgili olan makroekonomik göstergeler çalışmaya dâhil edilmeye çalışılmıştır.

BIST-100 Getiri Endeks verileri ${ }^{4}$ Borsa İstanbul'un internet sitesinden, TUIK Tüketici Güven Endeksi verileri ${ }^{5}$ Türkiye İstatistik Kurumunun resmi internet sitesinden, diğer değişken verileri ${ }^{6}$ T.C. Merkez Bankasının resmi internet sitesinin Elektronik Veri Dağıtım Sistemi’nden elde edilmiştir. Çalışmada Eviews 9,5 paket programı kullanılmıştır.

Araştırma yöntem itibariyle 2 aşamadan oluşmaktadır. Birinci aşamada, Ocak 2010 - Mart 2017 döneminde Hedonik Konut Fiyat Endeksi ve değişkenler arasındaki uzun dönem ilişkilere ARDL (Autoregressive Distibuted Lag) testi ile bakılacaktır.

Eşbütünleşme testlerinden en çok kullanılanı Engle-Granger (1987) ile Johansen (1988) ve Johansen ve Jesulius (1990) yöntemidir. Bu yöntemlerde tüm değişkenlerin düzeyde durağan olmaması ve birinci farklarda durağan olması gerekmektedir. Durağanlık dereceleri farklı olan verilere eşbütünleşme yöntemi uygulanamamaktadır. Pesaran ve Shin (1995) ve Pesaran vd. (2001) tarafindan geliştirilmiş olan ARDL sınır testi yaklaşımı bu sorunu çözmüştür. ARDL yöntemi değişkenlerin bütünleşme derecelerini dikkate alınmamaktadır ve değişkenler arasında eşbütünleşme ilişkisini araştırmaktadır. Sınır testi yöntemi kolaydır. Modelin gecikme uzunluğu En Küçük Kareler yöntemi ile tahmin edildikten sonra eşbütünleşme ilişkisine bakılmaktadır. Ayrıca, bu yöntem birim kök testi yapılan değişkenlerin ön testlerini gerektirmemektedir. Sınır testi küçük veya sınırlı örnek kümeleri için oldukça etkindir (Altıntaş, 2013: 11).

\footnotetext{
${ }^{4}$ http://borsaistanbul.com/veriler/verileralt/hisse-senetleri-piyasasi-verileri/piyasaverileri

${ }^{5}$ http://www.tuik.gov.tr/PreHaberBultenleri.do?id=13426

${ }^{6}$ http://evds.tcmb.gov.tr/cbt.html
} 
ARDL testinde kısıtsız hata düzeltme modeli kullanılmaktadır. Bu itibarla Engle Granger testine göre daha iyi istatistiksel modeldir. Johansen ve EngleGranger testlerine göre ise küçük örneklerde daha güvenilir sonuçlar vermektedir. Y bağımlı ve iki bağımsız değişkenli (E ve M) ARDL modelin yazılımı aşağıdaki şekilde tahmin edilmektedir.

$\Delta \mathrm{Y}_{t}=a_{0}+\sum_{i=1}^{m} a_{1 i} \Delta \mathrm{Y}_{t-i}+\sum_{i=0}^{m} a_{2 i} \Delta \mathrm{M}_{t-i}+\sum_{i=0}^{m} a_{3 i} \Delta \mathrm{E}_{t-i}+a_{4} \mathrm{Y}_{t-1}+a_{5} \mathrm{M}_{t-1}+a_{6} \mathrm{E}_{t-1}+u_{t}$

İkinci aşamada ise değişkenler arasındaki nedensellik ilişkileri Granger nedensellik testi ile araştırılacaktır. Granger Nedensellik Testi iki değişken arasında bir nedensellik ilişkinin olup olmadığını ve varsa bu ilişkinin yönünü belirlemek için kullanılan ekonometrik bir testtir.

\section{UYGULAMA VE BULGULAR}

Dickey ve Fuller (1981) tarafından geliştirilen, Augmented Dickey-Fuller (ADF) birim kök testi uygulanarak test edilmiş ve Tablo 1'de sunulmuştur. \% 1 anlamlılık düzeyinde imalat sanayi kapasite kullanım oranı (ISKKO) değişkeninin durağan, diğer değişkenlerin birim kök taşıdı̆̆ı, yani durağan olmadığı görülmektedir. Sanayi üretim endeksi (SUE) haricindeki değişkenler birinci farklarda durağan olmaktadır. Sanayi üretim endeksi (SUE) ise ikinci farklarda durağanlaşmaktadır. Bu değişkenlere ARDL sınır testi uygulanması anlamlı sonuçlar verecektir.

Tablo 1: ADF Test Tablosu

\begin{tabular}{|l|r|r|}
\hline Değişkenler & t-Statistic & Olasılık \\
\hline HKFE & 3.316252 & 1.0000 \\
\hline ALTIN & -0.143654 & 0.9404 \\
\hline BIST & -0.143654 & 0.8861 \\
\hline ISKKO & -4.270 .086 & 0.0009 \\
\hline RDK & -1.592 .710 & 0.4819 \\
\hline IO & -2.989 .730 & 0.0398 \\
\hline SUE & -2.408 .906 & 0.1428 \\
\hline TCMBBOG & -0.584225 & 0.8676 \\
\hline TUIKTGE & -2.739 .678 & 0.0716 \\
\hline USD & 1.111916 & 0.9974 \\
\hline
\end{tabular}




\section{AKKAYA}

Tablo 2'deki ARDL modelinde AIC kriteri kullanılarak maksimum gecikme uzunluğu 4 alınarak tahmin yapılmıştır. Tahmin sonucuna göre ARDL $(2,0,3,3,4,0,1,3,1)$ modeli seçilmiştir.

Tablo 2: ARDL (2,0,3,3,4,0,1,3,1) Modeli

Bağımlı Değişken: HKFE

Metod: ARDL

Model Seçme Metod: Akaike info criterion (AIC)

Dynamic regressors (4 lags, automatic): ALTIN BIST ISKKO IO RDK SUE TCMBBOG TUIKTGE USD

Seçilen Model: ARDL $(2,0,3,3,4,0,1,0,3,1)$

\begin{tabular}{|c|c|c|c|c|}
\hline Değişken & Katsayı & Std. Hata & t-Statistic & Prob.* \\
\hline HKFE(-1) & 1.223 .698 & 0.107250 & 1.140 .977 & 0.0000 \\
\hline HKFE(-2) & -0.280765 & 0.103775 & -2.705 .506 & 0.0091 \\
\hline ALTIN & 0.009070 & 0.007327 & 1.237 .783 & 0.2212 \\
\hline BIST & $-7.18 \mathrm{E}-07$ & 8.97E-06 & -0.080103 & 0.9365 \\
\hline BIST(-1) & $9.64 \mathrm{E}-06$ & $1.04 \mathrm{E}-05$ & 0.923110 & 0.3601 \\
\hline BIST(-2) & $1.15 \mathrm{E}-05$ & $1.03 \mathrm{E}-05$ & 1.110 .618 & 0.2717 \\
\hline BIST(-3) & $-2.25 \mathrm{E}-05$ & $1.02 \mathrm{E}-05$ & -2.204 .357 & 0.0318 \\
\hline BIST(-4) & $1.41 \mathrm{E}-05$ & 7.94E-06 & 1.770 .286 & 0.0823 \\
\hline ISKKO & 0.064841 & 0.071196 & 0.910739 & 0.3665 \\
\hline $\operatorname{ISKKO}(-1)$ & 0.091107 & 0.073414 & 1.241 .009 & 0.2200 \\
\hline ISKKO(-2) & 0.008810 & 0.062213 & 0.141612 & 0.8879 \\
\hline $\operatorname{ISKKO}(-3)$ & 0.138530 & 0.060924 & 2.273 .800 & 0.0270 \\
\hline $\operatorname{ISKKO}(-4)$ & 0.078909 & 0.060190 & 1.310 .994 & 0.1954 \\
\hline IO & -0.059070 & 0.083312 & -0.709016 & 0.4814 \\
\hline $\mathrm{IO}(-1)$ & -0.004474 & 0.108240 & -0.041335 & 0.9672 \\
\hline $\mathrm{IO}(-2)$ & -0.044091 & 0.100538 & -0.438555 & 0.6627 \\
\hline $\mathrm{IO}(-3)$ & 0.041638 & 0.112467 & 0.370227 & 0.7127 \\
\hline $\mathrm{IO}(-4)$ & 0.203741 & 0.088741 & 2.295 .908 & 0.0256 \\
\hline RDK & 0.044421 & 0.018130 & 2.450 .116 & 0.0176 \\
\hline SUE & -0.002374 & 0.007678 & -0.309157 & 0.7584 \\
\hline SUE(-1) & -0.018837 & 0.007480 & -2.518 .349 & 0.0148 \\
\hline TCMBBOG & 0.100376 & 0.025404 & 3.951 .124 & 0.0002 \\
\hline
\end{tabular}




\begin{tabular}{lrlrr} 
TUIKTGE & -0.028358 & 0.016113 & -1.759 .961 & 0.0841 \\
TUIKTGE(-1) & -0.026241 & 0.018559 & -1.413 .916 & 0.1631 \\
TUIKTGE(-2) & 0.030569 & 0.018773 & 1.628 .380 & 0.1093 \\
TUIKTGE(-3) & -0.038031 & 0.016892 & -2.251 .372 & 0.0285 \\
USD & -1.187 .311 & 0.700849 & -1.694 .104 & 0.0960 \\
USD(-1) & 1.929 .085 & 0.659456 & 2.925 .269 & 0.0050 \\
C & -4.435 .270 & 1.029 .490 & -4.308 .220 & 0.0001 \\
\hline R-squared & 0.999921 & Mean dependent var & 1.403 .900 \\
Adjusted R-squared & 0.999881 & S.D. dependent var & 3.125 .250 \\
S.E. of regression & 0.341333 & Akaike info criterion & 0.957024 \\
Sum squared resid & 6.291 .457 & Schwarz criterion & 1.802 .161 \\
Log likelihood & -1.071 .651 & Hannan-Quinn criter. & 1.296 .553 \\
F-statistic & 24549.00 & Durbin-Watson stat & 1.968 .549 \\
Prob(F-statistic) & 0.000000 & & \\
\hline \hline
\end{tabular}

*Note: p-values and any subsequent tests do not account for model selection.

Tablo 2'de değişkenlerin olasılık değerleri sunulmuştur. Yukarıdaki ARDL testi sonuçlarına göre eşbütünleşme ilişkisinin var olduğu anlaşılmaktadır. 9 değişkenin bağımsız değişken olduğu modelde, 8 değişken ile Hedonik Konut Fiyat Endeksi arasında eşbütünleşme ilişkisi vardır.

Altın fiyatı hariç diğer değişenlerin istatistiksel olarak anlamlı olduğu $(\mathrm{P}=0.0000)$ görülmektedir. Söz konusu modelinin belirginlik katsayısı (Adjusted R-squared), yani modelin açıklama gücü 0,9999 olarak belirlenmiştir. Sonuçlara göre Hedonik Konut Fiyat Endeksini bu dönemde pozitif olarak en çok 1 ay gecikme ile USD dolar kuru (katsayı1,92) etkilemektedir. Ayrıca 4. gecikmede İşsizlik Oranı $(0,20)$, 3. gecikmede İmalat Sanayi Kapasite Kullanım Oranı $(0,13)$, düzey seviyede TCMBBOG $(0,10)$ ve düzey seviyede TÜFE bazlı Reel Kur Endeksi $(0,04)$ etkilemektedir. Negatif olarak ise Borsa İstanbul Getiri endeksi 3. gecikmede etkilemektedir (katsayısı - 2,25). Ayrıca, 3. gecikmede TUIK Tüketici Güven endeksi $(0,03)$ ve 1 . gecikmede Sanayi Üretim endeksi $(0,01)$ negatif etkilemektedir. Bu sonuç Altın Fiyatı hariç belirlenen diğer 


\section{AKKAYA}

değişkenlerin Hedonik Konut Fiyat Endeksi üzerinde etkili olduğunu göstermektedir.

İkinci aşamada değişkenler arasındaki nedensellik ilişkilerine bakmak için Granger nedensellik testi kullanılmıştır. Granger Nedensellik Testi için değişkenlerin durağan olması gerekmektedir. Durağan zaman serilerinin Granger nedensellik sınamasında değişkenlerin düzey değerleri kullanılmaktadır. Durağan olmayan değişkenlerin birinci (veya daha yüksek) farkları kullanılarak yapılacaktır. Testdeki gecikme sayısı Akaike veya Schwarz Bilgi kriterleri kullanılarak seçilmektedir.

H0: x, y nin Granger nedeni değildir" temel hipotezi:

(1) y'nin tek değişkenli bir öz bağlanımındaki y'nin uygun gecikmeli değerleri (gecikme say1s1) bulunur:

$$
y_{\mathrm{t}}=\alpha_{0}+\alpha_{1} \mathrm{y}_{\mathrm{t}-1+\alpha_{2} \mathrm{y}_{\mathrm{t}-2}+\ldots \ldots \ldots+\mu}
$$

(2) y’nin öz bağlanımı, x’in gecikmeli değerleri katılarak genişletilir:

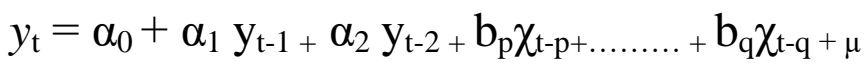

$$
\begin{aligned}
& \text { p: en kısa gecikme uzunluğu } \\
& \text { q: en uzun gecikme uzunluğu }
\end{aligned}
$$

x'in t-sınamalarına göre tek başına anlamlı olan tüm gecikmeli değerleri, gecikmeler birlikte bir F-sınamasına göre bağlanımın açıklayıcı gücüne güç katarsa korunmaktadır.

Granger Nedensellik Testi için değişkenlerin durağan olması gerekmektedir. Altın Fiyatı, BIST100 Getiri Endeksi, İşsizlik Oranı, İmalat Sanayi Kapasite Kullanım Oranı, Rezervler, Sanayi Üretim Endeksi ve TUIK Tüketici Güven Endeksi değişkenleri düzey seviyede durağan olmadığından 1. derece farkları alınıp durağanlaştırılmıştır. Granger Nedensellik Testinde olasılık değerleri 0,05'den küçük ise değişkenler arasında nedensellik ilişkisi bulunmaktadır ve ilişkinin yönünü göstermektedir. 
Granger Nedensellik Testinde uygun gecikme sayısının belirlenmesi gerekir. Akaike Bilgi Kriteri (AIC), Hannan-Quinn Bilgi Ktiteri (HQ) ve LR doğrultusunda en küçük olan 2 (iki) olarak belirlenmiştir (Tablo 3) .

Tablo 2: Gecikme Uzunluk Kriteri

VAR Lag Order Selection Criteria

Değişkenler: HKFE ALTIN BIST IKKO IO RDK SUE TCMBBOG TUIKTGE USD Gözlem say1sı: 83

\begin{tabular}{ccccccc}
\hline \hline Lag & LogL & LR & FPE & AIC & SC & HQ \\
\hline \hline 0 & -2616.706 & NA & $1.46 \mathrm{e}+15$ & 63.29413 & 63.58556 & 63.41121 \\
1 & -1843.791 & 1340.962 & $1.34 \mathrm{e}+08^{*}$ & 47.07929 & 50.28498 & 48.36716 \\
2 & -1753.033 & $135.5896^{*}$ & $1.85 \mathrm{e}+08$ & $47.30200^{*}$ & 53.42196 & $49.76066^{*}$ \\
3 & -1653.827 & 124.3062 & $2.46 \mathrm{e}+08$ & 47.32114 & 56.35536 & 50.95058 \\
4 & -1556.435 & 98.56555 & $4.62 \mathrm{e}+08$ & 47.38398 & 59.33247 & 52.18421 \\
\hline \hline
\end{tabular}

* gecikme sayısı seçim kriteri

LR: sequential modified LR test statistic (each test at 5\% level)

FPE: Final prediction error

AIC: Akaike information criterion

SC: Schwarz information criterion

HQ: Hannan-Quinn information criterion

Granger Nedensellik Testi sonuçlarına göre (Tablo 4) Altın Fiyat1, BIST100 Getiri Endeksi, İșsizlik Oranı, TÜFE bazlı Reel Kur Endeksi Hedonik Konut Fiyat Endeksinin Granger nedenidir ve aralarında tek yönlü Granger nedensellik saptanmıştır. Hedonik Konut Fiyat Endeksi ise Sanayi Üretim Endeksini etkilemektedir. Hedonik Konut Fiyat Endeksi ile TÜİK Tüketici Güven Endeksi arasında çift yönlü (karşılıklı) nedensellik ilişkisi bulunmaktadır. 


\section{AKKAYA}

Tablo 4: Granger Nedensellik Testi Sonuçları

\begin{tabular}{|c|c|c|c|}
\hline Değişken & F Değeri & $\begin{array}{l}\text { Olasılık } \\
\text { Değeri }\end{array}$ & Sinama Sonucu \\
\hline ALTIN - HKFE & 1.45671 & 0.2391 & \\
\hline HKFE - ALTIN & 5.64295 & 0.0051 & $\begin{array}{l}\text { Altın Fiyatından HKFE'ne (Tek } \\
\text { Yönlü) }\end{array}$ \\
\hline BIST - HKFE & 2.97926 & 0.0565 & \\
\hline HKFE- BIST & 3.54406 & 0.0335 & $\begin{array}{l}\text { BIST } 100 \text { Getiri Endeksinden } \\
\text { HKFE'ne (Tek Yönlü) }\end{array}$ \\
\hline ISKKO - HKFE & 0.00270 & 0.9973 & \\
\hline HKFE- ISKKO & 0.24031 & 0.7870 & \\
\hline IO - HKFE & 0.37106 & 0.6912 & \\
\hline HKFE- IO & 6.35315 & 0.0027 & $\begin{array}{l}\text { İşsizlik Oranından HKFE'ne (Tek } \\
\text { Yönlü) }\end{array}$ \\
\hline RDK - HKFE & 0.79674 & 0.4543 & \\
\hline HKFE- RDK & 3.09844 & 0.0506 & $\begin{array}{l}\text { Reel Döviz Kurundan HKFE'ne } \\
\text { (Tek Yönlü) }\end{array}$ \\
\hline SUE - HKFE & 6.60187 & 0.0022 & $\begin{array}{l}\text { HKFE'nden Sanayi Üretim Endeksi } \\
\text { (Tek Yönlü) }\end{array}$ \\
\hline HKFE- SUE & 16.5028 & 1.E-06 & \\
\hline TCMBBOG - HKFE & 1.77240 & 0.1765 & \\
\hline HKFE- TCMBBOG & 2.48511 & 0.0897 & \\
\hline TUIKTGE -HKFE & 4.98539 & 0.0091 & $\begin{array}{l}\text { TUIK Tüketici Güven Endeksi ve } \\
\text { HKFE (Çift Yönlü) }\end{array}$ \\
\hline HKFE- TUIKTGE & 6.35524 & 0.0027 & $\begin{array}{l}\text { TUIK Tüketici Güven Endeksi ve } \\
\text { HKFE (Çift Yönlü) }\end{array}$ \\
\hline
\end{tabular}

\section{SONUÇ VE ÖNERILER}

Konut piyasası son yıllarda ekonomi içerisinde önemli bir paya sahiptir. Ayrıca konut piyasasının finansal piyasalarla da önemli bir etkileşimi bulunmaktadır. Konut piyasalarındaki değişimler para ve maliye politikaları etkilemektedir.

Çalışmanın amacı Hedonik Konut Fiyat Endeksi ve makroekonomik değişkenler arasındaki uzun dönemli ilişkinin incelenmesi ve değişkenler arasındaki nedensellik ilişkilerinin belirlenmesidir. ARDL $(2,0,3,3,4,0,1,3,1)$ modeli seçilmiştir. Uzun dönemde Altın Fiyatı hariç çalışmada kullanılan ve modele eklenen Borsa İstanbul getiri endeksi, imalat sanayi kapasite kullanım 
oranı, işsizlik oranı, TÜFE bazlı Reel Kur Endeksi, sanayi üretim endeksi, T.C. Merkez Bankası Bileşik Öncü Gösterge, TUİK Tüketici Güven Endeksi, tüketici fiyatları fiyat endeksi, USD döviz kurunun uzun dönemde Hedonik Konut Fiyat Endeksi üzerinde etkili olduğunu göstermektedir. İkinci aşamada Granger nedensellik testi kullanılmış ve Granger Nedensellik Testi sonuçlarına göre değişkenler arasında nedensellik ilişkileri tespit edilmiştir. Granger Nedensellik Testi sonuçlarına göre Altın Fiyatı, BIST100 Getiri Endeksi, İşsizlik Oranı, TÜFE bazlı Reel Kur Endeksi Hedonik Konut Fiyat Endeksinin Granger nedenidir ve aralarında tek yönlü Granger nedensellik saptanmıştır. Hedonik Konut Fiyat Endeksi ise Sanayi Üretim Endeksini etkilemektedir. Hedonik Konut Fiyat Endeksi ile TÜİK Tüketici Güven Endeksi arasında çift yönlü (karşılıklı) nedensellik ilişkisi bulunmaktadır.

Yapılan yazın taramasında Türkiye'de konut piyasasında Hedonik Konut Fiyat Endeksi ve makroekonomik değişkenler arasındaki uzun dönemli ilişki hakkında çalışmalara rastlanılmamıştır. Çalışmalar genellikle amacı Hedonik Konut Fiyat Endeksi oluşturma ve şehirler bazında amacı Hedonik Konut Fiyat Endeksi'ni etkileyen faktörlerin belirlenmesi üzerinedir. $\mathrm{Bu}$ itibarla bu çalışmanın yapılacak diğer çalışmalara 1şık tutacağı düşünülmektedir. Ayrıca Hedonik Konut Fiyat Endeksi Ocak 2010 tarihinden itibaren açıklanmaktadır. Bu sebeple kullanılan veri sayısı sınırlıdır. İlerleyen dönemlerde benzer veya başka modellerle tekrar çalışılmasında fayda olacağı düşünülmektedir.

\section{KAYNAKÇA}

Altıntaş, H. (2013)," Türkiye'de petrol fiyatları, ihracat ve reel döviz kuru ilişkisi: ARDL sınır testi yaklaşımı ve dinamik nedensellik analizi”. Uluslararası Yönetim Íktisat ve İsletme Dergisi, 9(19), 1-30.

Arora, M. V. B. \& Cerisola, M. M. D. (2000), "How does US monetary policy influence economic conditions in emerging markets?", International monetary fund. 0-148. 


\section{AKKAYA}

Badurlar, İ. 0. (2008), "Türkiye'de Konut Fiyatları İle Makro Ekonomik Değişkenler Arasındaki İlişskinin Araştırılması”, Anadolu Üniversitesi Sosyal Bilimler Dergisi, 8 (1):223-238.

Baldemir, E, Kesbiç, C.Y. ve İnci, M. (2008), "Estimating Hedonik Demand Parameters In Real Estate Market: The Case Of Muğla", Sosyal Bilimler Enstitüsü Dergisi, 20, 41-66.

Bartik, T. J. (1987), "Estimating Hedonic Demand Parameters With Single Market Data: The Problems Caused By Unobserved Tastes", The Review Of Economics And Statistics. 69, 1, 178-180.

Bekmez, S. ve Özpolat, A. (2013), “Gelir Esnekliğinin ve Kentsel Dönüşüm Uygulamalarının Konut Talebine Etkisinin VECM Yöntemi İle Tahmin Edilmesi”, Akdeniz İI.I.B.F. Dergisi, (27), 99-113.

Bourassa, S. C., Cantoni, E. ve Hoesli, M. (2007), "Spatial Dependence, Housing Submarkets And House Price Prediction", Journal Of Real Estate Finance And Economics, 35,143-160.

Bover, O. ve Velilla, P. (2002), "Hedonic House Prices Without Characteristics: The Case Of New Multiunit Housing", ECB Çalışma Tebliği Serisi. No:117.

Cingöz, A.R.A.A, (2010), "İstanbul'da Kapak Site Konut Fiyatlarının Analizi”, Sosyal Bilimler Dergisi. 2, 129-139.

Court, A. (1939), "Hedonic Price Indexes with Automotive Examples", The Dynamics of Automobile Demand, 99-117.

Dickey, D. A.\& Fuller, W. A. (1981), "Likelihood ratio statistics for autoregressive time series with a unit root. Econometrica. 49(4), 1057-72.

Engle R. F. \& Granger, C. W. J. (1987), "Co-integration and error correction: representation, estimation and testing", Econometrica, 55, 251-76. 
Filho, C. M. ve Bin, O. (2003), "Estimation Of Hedonic Price Functions Via Additive Nonparametric Regression", Empirical Economics. 30, 93-114.

Goodman, A. C. (1978), "Hedonic Prices, Price Indices And Housing Markets", Journal Of Urban Economics, 5, 471-484.

Goodman, A. C. (1998), "Andrew Court And The Invention Of Hedonic Price Analysis", Journal Of Urban Economics. 44, 291-298.

Griliches, Z. (1961), "Hedonic Price Indexes for Automobiles: An Econometric Analysis of Quality Change", National Bureau of Economic Research and University of Chicago. 0-87014-072-8, 173-196.

Hill, R. J. (2011). "Hedonic Price Indexes for Residential Housing: A Survey, Evaluation and Taxonomy”. OECD Statistics Çalışma Tebliği, 39, 2011-1.

Johansen, S. \& Juselius, K. (1990), "Maximum likelihood estimation and inference on cointegration - with applications to the demand for Money", Oxford Bulletin of Economics and Statistics, 52, 169-210.

Johansen, S. (1988), "Statistical analysis of cointegration vectors", Journal of Economic Dynamics and Control. 12, 231-254.

Kain, J. F. ve Quigley, J. M. (1970), "Measuring The Value Of Housing Quality", Journal Of The American Statistical Association. 65, 330,532-548.

Karg1, B. (2013), "Konut Piyasası ve Ekonomik Büyüme İlişkisi: Türkiye Üzerine Zaman Serisi Analizileri”, International Journal of Duman Sciences. $10,1,897-924$

Kaya, A. (2012), “Türkiye'de Konut Fiyatlarını Etkileyen Faktörlerin Hedonik Fiyat Modeli ile Belirlenmesi”, TCMB Uzmanlık Tezi. Ankara.

Kim, S. (1992), "Hedonic Prices And Housing Demand", The Review of Economics And Statistics, 74, 3, 503-508. 


\section{AKKAYA}

Kördiş, G., Işı1k, S., \& Mert, M. (2014), “ANTALYA'DA KONUT FIYATLARINI ETKILEYEN FAKTÖRLERIN HEDONIK FIYAT MODELI İLE TAHMIN EDILLMESI", Akdeniz University Faculty of Economics \& Administrative Sciences Faculty Journal/Akdeniz Universitesi Iktisadi ve Idari Bilimler Fakultesi Dergisi, 14(28).

Kunovac, D., Đozović, E., Lukinić, G., ve Pufnik, A. (2008), "Use of the Hedonic Method to Calculate an Index of Real Estate Prices in Croatia", Hirvatistan Merkez Bankası Çalışma Tebliği. W-19.

Leishman, C. (2001), "House Building And Product Differentiation: An Hedonic Price Approach", Journal Of Housing And The Built Environment. 16,131-152.

Li, W., Prud'homme, M. ve Yu, K. (2006), "Studies In Hedonic Resale Housing Price Indexes", OECD-IMF Workshop on Real Estate Price Indexes, Paris.

Mendelsohn, R. (1984), "Estimating The Structural Equations Of Implicit Markets And Household Production Functions", The Review Of Economics and Statistics. 66, 4, 673-677.

Mutluer, D., (2008), “Gayrimenkul Fiyadarının Derlenmesi Ülke Örnekleri ve Türkiye İçin Bir Uygulama”, TISK Akdemi, 2008/11, 240-278.

Ogwang, T. ve Wang B. (2002), "A Hedonic Price Function For A Northern BC Community”, Social Indicators Research. 6, 285-296.

Palmquist, R. B., (1984), "Estimating The Demand For The Characteristics Of Housing", The Review Of Economics And Statistics, 66, 3, 394-404.

Pesaran, H., \& Shin Y. (1995), "An Autoregressive Distributed Lag Modelling Approach to Cointegration Analysis”, S. Strom, A. Holly ve A. Diamond (Eds.), Centennial Volume of Ranger Frisch, Cambridge University Press.

Ridker, R. G. \& Henning, J.A. (1967 May), "The Determinants of Residential Property Values With Special Reference to Air Pollution", Review of Economics and Statistics.49,246--257. 
Rosen, S. (1974), "Hedonic Prices and Implicit Markets: Product Differentiation in Pure Competition", The Journal of Political Economy. 82, 34-55.

Selim, S. (2008), "Determinants O f House Prices In Turkey: A Hedonic Regression Model", Doğuş Üniversitesi Dergisi, 9,1, 65-76.

Selim, S. ve Demirbilek, A. (2009), "Türkiye'deki Konutların Kira Değerinin Analizi: Hedonik Model ve Yapay Sinir Ağları Yaklaşımı”, Aksaray Üniversitesi iktisadi ve idari Bilimler Eakültesi Dergisi. 73-90.

Shimizu, C., Takatsuji, H. ve Ono, H. (2010), "Structural And Temporal Changes In The Housing Market And Hedonic Housing Price Indices: A Case Of The Previously Owned Condominium Market In The Tokyo Metropolitan Area", International Journal Of Housing Markets and Analysis. 3, 4, 351-368.

Straszheim, M. R. (1973), "Estimation Of The Demand For Urban Housing Services From Household Interview Data", The Review Of Economics And Statistics. 55, 1, 1-8.

Straszheim, M. R. (1974), "Hedonic Estimation Of Housing Market Prices: A Further Comment", The Review Of Economics And Statistics, 56, 3,404-406.

T.C. Merkez Bankası (2016), "Türkiye Konut Fiyat Endeksi'nin Kalite Değişimi Etkisinden Arındırılması: Hedonik Konut Fiyat Endeksi”, TCMB Ekonomi notlarl, 02.

Üçdoğruk, Ş. (2001), "İzmir İlinde Emlak Fiyatlarına Etki Eden Faktörler Hedonik Yaklaşım”, D.E.Ü.I.I. . B.F Dergisi. 16,2, 149-161.

Yankaya, U. \& Çelik, M. (2005), "Modeling the Impact of Izmir Subway on the Housing Values with Hedonic Price Model", Dokuz Eylül University IIIBF Magazine. 20(2), 61-79.

Waugh, F. W. (1928), "Quality Factors Influencing Vegetable Prices”, Journal of Farm Economics. 10/2, 185-196. 


\section{AKKAYA}

Wilhelmsson, M. (2008), "Construction And Updating Of Property Price Index Series: The Case Of Segmented Markets In Stockholm", Property Management. 27, 2, 119-137.

Widlak, M. ve Tomczyk, E. (2010), "Measuring Price Dynamics: Evidence From The Warsaw Housing Market", Journal Of European Real Estate Research. 3, 3, 203-227. 